\title{
Auditory Brainstem Responses (ABR) changes in children treated with high doses cisplatin
}

Lucas Moura Viana' Andre L L Sampaio²

Nilda Agostinho Maia²

Rozania M P Junqueira ${ }^{3}$

Alessandra Ramos Venosa ${ }^{2}$ Carlos Augusto C P Oliveira

\begin{abstract}
Introduction: Cisplatin can cause cochlear damage by oxidative stress in hair cells, but there are few studies regarding toxicity in the central auditory pathways. Objective: To study cisplatin neurotoxicity in the central auditory pathways in children treated with high doses cisplatin for solid malignant tumors. Methods: Thirteen children (Group S) aged 3-19 years who had been treated with cisplatin $\left(60-120 \mathrm{mg} / \mathrm{m}^{2} /\right.$ cycle) were studied using evoked otoacoustic emissions (EOA), conventional auditory evaluation and auditory brainstem response (ABR). Thirteen normal children matched for age and sex composed the control group (Group C). Results: Group S - 7.5\% percent of ears showed enlargement of latencies of waves I and V, and $3.8 \%$ of wave III. Six ears (23\%) showed enlarged interpeak intervals. Four ears showed increased interpeak I-III and two showed increased interpeak III-V. The results were compared using the Mann-Whitney test. Interpeak III-V differed significantly between groups $S$ and $C$ when only the left ears were considered. EOA results were normal in both groups. Discussion/Conclusion: Abnormal values in the interpeak I-III associated with normal distortion product OEA suggest neurotoxicity in the brainstem pathways. The statistical significance reached only in the left ear may be due to small number of cases studied.
\end{abstract}

Keywords: auditory, brain stem, cisplatin, evoked potentials, hearing loss.

\footnotetext{
${ }^{1}$ Faculty of Health Sciences - University of Brasília - Brasília - DF - Brasil. E-mail: lucasmvianaorl@gmail.com

2 Department of Otorhinolaryngology - University Hospital of Brasília - University of Brasília - Brasília - DF - Brasil. E-mail: andremarjy@uol.com.br.

E-mail: rozania@unb.br. E-mail: saan70@gmail.com.E-mail: nilmaia@hotmail.com.

${ }^{3}$ Department of Statistics - University Hospital of Brasília - University of Brasília - Brasília - DF - Brasil. E-mail: nilmaia@hotmail.com

${ }^{4}$ Professor Emeritus at University of Brasilia - Brasília - DF - Brasil. E-mail: cacpoliveira@brturbo.com.br

Institution: University Hospital of Brasília - University of Brasília.

Send correspondence to:

André Luiz Lopes Sampaio.

SHIGS 706 Bloco P casa 76. Phone:55-61- 34433397. Fax:55-61- 34433397. E-mail:andremarjy @uol.com.br

Paper submitted to the ITJ-SGP (Publishing Management System) on September 18, 2013;

and accepted on October 18, 2013. cod. 132.
} 


\section{INTRODUCTION}

Cisplatin is a chemotherapeutic agent used in the treatment of several solid malignant tumors like carcinomas, sarcomas, lymphomas, malignant melanomas, hepatoblastomas, neuroblastomas and osteossarcomas. Ototoxicity of cisplatin is well documented and is related to oxidative stress of hair cells in the cochlea and vestibule ${ }^{1,2}$. Some studies ${ }^{3,4}$ have reported cisplatin toxicity to the central nervous system. However, very litle is known about cisplatin toxicity to the central auditory pathways.

The American Speech-Language-Hearing Association stated that all patients on cisplatin treatment should be evaluated for hearing loss before or at least $24 \mathrm{hs}$ after the beginning of treatment ${ }^{5}$. Fausti et al. ${ }^{6}$ in 1984 already recommended the elaboration of an audiological protocol to be applied to patients on cisplatin treatment for malignant tumors.

Patients on high doses cisplatin treatment present sensorineural hearing loss and low discrimination of words ${ }^{7}$. Cisplatin ototoxicity for the cochlea and vestibule is well described and documented ${ }^{6,8-11}$. Distortion product evoked otoacoustic emissions (DPEOAE) has shown dysfunction of outer hair cells as a result of cisplatin treatments for malignant tumors. Cisplatin neurotoxicity for the central auditory pathways has been poorly studied up to now.

Auditory brainstem responses (ABR) is a non-invasive, reproducible and reliable electrophysiologic test for the study of the central auditory pathway from the cochlear nerve up to the mesencephalus ${ }^{12}$. It is therefore a suitable test to study cisplatin toxicity to the central auditory pathways from the cochlear nerve to the low mesencephalus.

We studied the central auditory pathway of children treated with high doses cisplatin for solid malignant tumors using the ABR protocol currently recommended in attempt to assess central neurotoxicity of this commonly used chemotherapeutic drug.

\section{PATIENTS AND METHODS}

The study was performed at University Hospital of Brasilia Medical School, Brazil and involved children being treated with high doses cisplatin for solid malignant tumors at Public Department of Health, Brasília, Brazil, a facility specialized on pediatric cancer care. All included patients had permission to participate, and a consent form was signed by the parents or caretakers after all the information about the study was explained to them.

The study group (S) included children from 3 to 18 years who were treated with cisplatin doses from 60 to $120 \mathrm{mg}$ per square meter per cycle. Children who had any previous otologic problem or had been treated with any ototoxic drug in the past were excluded. These children had normal hearing before treatment according to interview with parents and caretakers and had not have any otologic problem but they were not examined before starting the chemotherapy protocol as this was not a prospective study.

The control group (C) was formed by children who have never used cisplatin or any other ototoxic drug, and they were matched by age and sex with the children in the study group. The inclusion criteria for this group were: 1) Hearing thresholds from 250 to $8000 \mathrm{Khz}$ equal or below to $15 \mathrm{~dB}$; 2) Absence of middle ear, neurologic or cardiovascular diseases; 3) Negative history of noise exposure; as well as no history of vertigo or treatment of this symptoms in the last six months.

Group C - Standard audiometry, vocal audiometry, tympanometry, DPEOAE, and ABR were performed in all patients of the group. Model aud-plus from Biologic was used to perform the audiometric evaluation. The Ep 25 equipment from Interacoustics was used to perform the ABR examination. All patients were examined At the audiologic clinic of the Otolaryngology Department at the University of Brasilia Medica School.

Group S - All patients underwent all tests mentioned for group $\mathrm{C}$ after finishing their chemotherapy protocol with high doses of cisplatin.

All tests were performed by one Audiologist assisted by two of the authors (LMV and ALLS) following the same protocol in the same equipment, and in an electrically shielded room in order to eliminate all possible artifacts. Each ear and central auditory pathways was evaluated separately. The criteria for normalcy adopted were described by $\mathrm{Hall}^{13}$. The active electrode was positioned in the frontal area, the reference one was positioned in the ipsilateral mastoid process and the neutral one was positioned in the opposite mastoid process in order to register the brainstem evoked potentials. The stimulus employed was a click with frequencies from 2000 to $4000 \mathrm{~Hz}$ in 80 $\mathrm{dB}$. The potentials were recorded during the first $12 \mathrm{~ms}$. Absolute latencies of waves I, III and V and interpeak intervals I-III. III-V and I-V were recorded and analyzed in the result section.

Statistical analysis was performed by using the Mann-Whitney test and significancy was considered when $P<0.05$. The SPSS software (version 20.0) was employed. As both groups were matched for age and sex we compared left side and right side from each group in relation to the results of the tests described.

\section{RESULTS}

Group S had 13 patients, 7 male and 6 female. Group $\mathrm{C}$ had 13 patients matched for age and gender. Both groups had ages between 3 and 18 years (Table 1 ). The average age for both groups was 11.47 years. 
Table 1. Group S: latencies of waves I,III and V, and of interpeaks I-III, III-V and I-V.

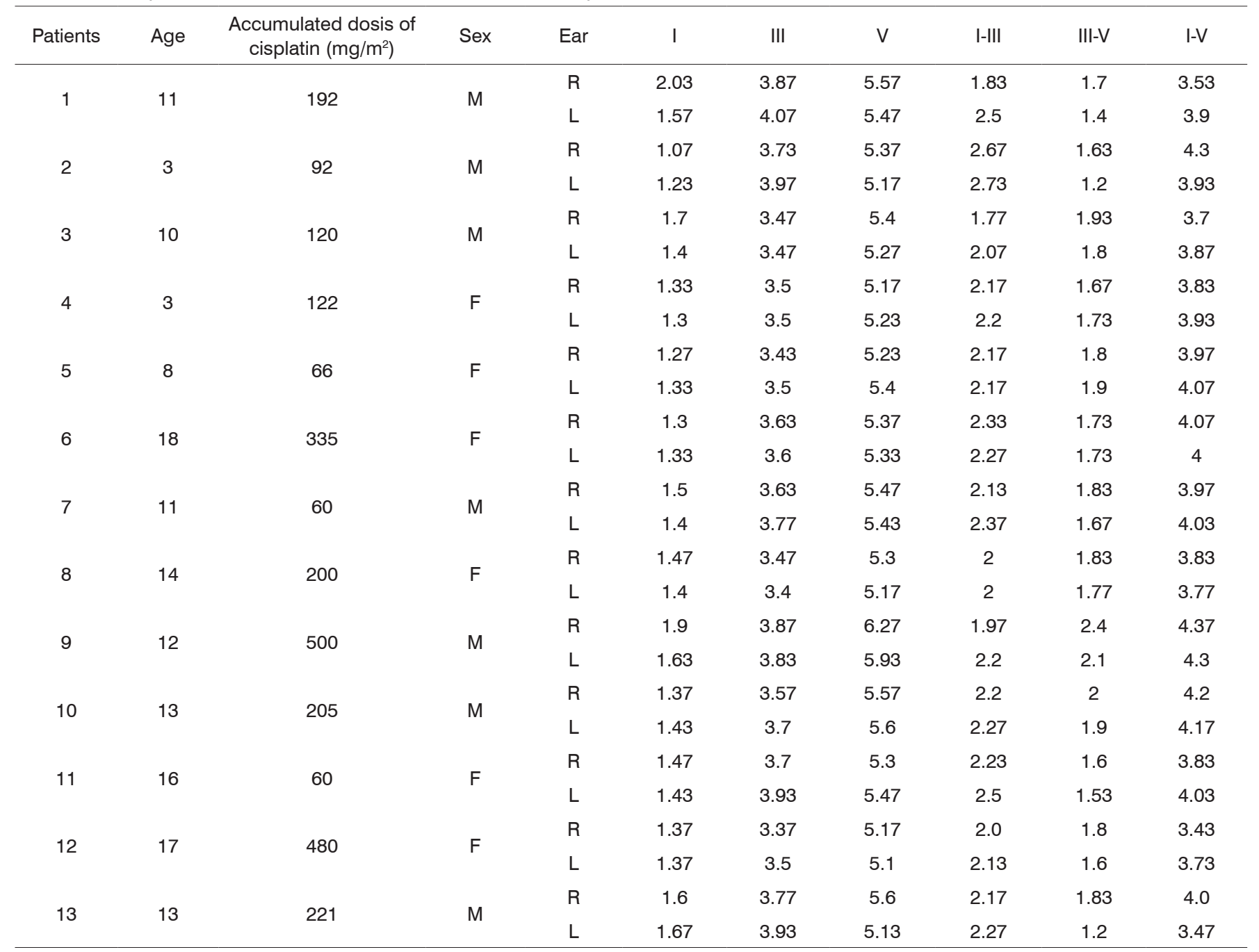

M: Male, F: Female, R: Right, L: Left.

Group S - patients had undertaken high cisplatin doses ranging from 60 to $120 \mathrm{mg} / \mathrm{m}^{2} /$ cycle of chemotherapy and accumulated doses from 60 to $480 \mathrm{mg} / \mathrm{m}^{2}$ (Table 1). Twenty-six ears were analyzed. Group C was composed by patients who had not used cisplatin and were otherwise matched to their Group S counterparts. Twenty-six ears were also analyzed. The follow up period in Group S ranged from one to 144 months and only three patients (six ears) were analyzed after 24 months the beginning of cisplatin treatment and 10 (twenty ears) were analyzed before 12 months after the treatment with cisplatin.

Group S - when compared with reference values ${ }^{14}$ one patient had lengthening of absolute latency of waves $\mathrm{I}$ and V. Another patient had lengthening of absolute latency of wave I of right ear and of wave III of the left ear. Therefore the percentage of ears with altered absolute latencies in Group S was $7.6 \%$ for waves I and $\mathrm{V}$ and $3.8 \%$ for wave III. Four ears had lengthening of interpeak I-III, two of interpeak III-V, none had lengthening of interpeak I-V. Therefore, Twenty three percent of ears had interpeak alterations in a total of four patients in Group S (Table 1). Two of these four patients had follow up below 12 months of duration and two had more than 24 months follow up after cisplatin treatment. Two of these four patients had hearing thresholds above $15 \mathrm{~dB}$ in both ears at the frequencies of $6000 \mathrm{~Hz}$ and $8000 \mathrm{~Hz}$, and DPEOAE absent in all frequencies evaluated. Of Nine patients who did not have any change in $A B R$ results six had hearing thresholds above $15 \mathrm{~dB}$ in at least one of the ears in $6000 \mathrm{~Hz}$ and $8000 \mathrm{~Hz}$ and of these only two had absent DPEOAE in one or more frequencies examined. Tympanometry was normal in all ears.

Group C had normal results in all tests performed.

Statistical analysis using the Mann-Whitney test and SPSS software and by comparing the results of absolute latencies of waves I, III and V and interpeaks I-III, III-V and I-V of Groups S and C showed significant 
statistical difference between groups only for interpeaks III-V of the left ear comparisons (Table 2).

Table 2. Statistical Comparison between Groups $S$ and $C$.

\begin{tabular}{lcccccc}
\hline Ear & I & III & V & I-III & III-V & I-V \\
\hline Right & 0.920 & 1.000 & 1.000 & 0.960 & 0.687 & 0.801 \\
Left & 0.511 & 0.186 & 0.362 & 0.101 & 0.022 & 0.801 \\
\hline
\end{tabular}

\section{DISCUSSION}

Ototoxicity is a characteristic of platinum derived antineoplastic drugs. Specially in children it is important to achieve early diagnosis and intervention in order to avoid the handicap of hearing loss for the patient ${ }^{14,15}$. Ototoxicity of cisplatin for the cochlea and vestibule have been well studied but there are few studies on the side effects of cisplatin in the central auditory pathways.

Hansen et al. ${ }^{16}$ studied 30 patients treated for solid malignant tumors with cisplatin, bleomicin and vinblastin. Twenty-two out of 30 patients had hearing loss $(73 \%)$. ABR results showed normal latency of wave I and a lenghtening of interpeak I-V, which was statistically significant $(P<0.01)$ when compared to normal population. He suggested that toxicity of the chemotherapeutic drugs had a central component involving the auditory pathways.

In this study, seventy seven percent of group $S$ patients had sensorineural hearing loss, according to standard audiometry. Interpeak I-III was enlarged in at least one ear of patients 1,2 and 11. However when we compared groups $\mathrm{S}$ and $\mathrm{C}$ there was no statistically significant difference between the two groups in relation to interpeak I-III ( $P=0.96$ for right ear and 0.10 for left ear). Patient 9 had enlargement of interpeak III-V in both ears and when we compared groups $\mathrm{S}$ and $\mathrm{C}$ there was statistically significant difference between left ears regarding interpeak III-V $(P=0.022$ for left ear and 0.687 for right ear). Furthermore patient 9 had normal audiometry and DPEOAE in both ears. These results taken together suggest the possibility of central auditory neurotoxicity of cisplatin.

Two out of four patients displaying changes in $A B R$ results were evaluated 12 months after cisplatin treatment and two others with similar ABR alterations were examined 24 months after the same treatment. These results might suggest that there is no relation between ABR changes and the follow up time after cisplatin treatment as suggested by Hansen et al. ${ }^{16}$.

The ototoxicity of cisplatin has been well studied in the temporal bone. Animal studies have shown pathologic changes in the organ of Corti, spiral ganglion, stria vascularis and spiral ligament ${ }^{17}$. Demyelization of the spiral ganglion cells ${ }^{18}$, edema, rupture and loss of cytoplasmatic organelles in the stria vascularis ${ }^{19}$, apoptosis of the spiral ligament ${ }^{20,21}$ have been described. Cisplatin also blocks the generation of antioxidants enzymes producing reactive oxygen radicals and leads to apoptosis of the outer hair cells $\mathbf{s}^{22,23}$.

Several studies ${ }^{24-26}$ have shown a cumulative doses of 300 to $400 \mathrm{mg} / \mathrm{m}^{2}$ are more often associated with ototoxicity. Our patients had cumulative doses from 60 to $480 \mathrm{mg} / \mathrm{m}^{2}$ and we could not find a doses related toxicity. Moreover, children are considered to be more vulnerable to cisplatin toxicity and patients younger than 5 years old are particularly vulnerable ${ }^{27}$.

A direct effect of cisplatin on the central auditory pathways could explain our finding: $31 \%$ of our patients had interpeak abnormalities. However, a quantitative analysis, in another study, only small percentage of the cisplatin doses crosses the blood-brain barrier. Some speculate that blood supply to the central pathways is reduced by a vaso-spastic action of cisplatin or by direct toxicity to the blood vessels ${ }^{16}$.

It is important in the pediatric population undergoing chemotherapy with cisplatin to monitor the ototoxicity effect during the therapy. Otolaryngologist, Audiologist and Psychologist must be available to monitor these patients during their treatment and a protocol must be elaborated in each chemotherapeutic Center for this endeavor.

Conventional audiologic evaluation must be part of this protocol. DPEOAE and ABR are also important. Some authors state $A B R$ can detect prolonged waves in patients on chemotherapy before hearing loss begins. However the size of the samples studied by these authors was too small and no definitive statement can be made at this point ${ }^{28,29}$.

High frequency audiometry could improve the monitoring of these patients according to some authors. Others state that tone burst ABR is more effective in detecting impending hearing loss than click ABR. Brainstem evoked response audiometry (BERA) has also been tried in young children to detect early cisplatin ototoxicity but apparently was less sensible than conventional audiometry in this regard problably because of the high incidence of middle ear disease in this population ${ }^{10}$.

One limitation of our study is not having a baseline evaluation of the group $S$ patients before starting the chemotherapy. However the inclusion criteria for this group was very severe in excluding any patient with previous otologic problems or suspected hearing loss. This rigid criteria led to the small number of patients studied which is the second limitation of this work. Our findings must be considered therefore preliminary but we believe they suggest the need for prospective well controlled studies with larger number of patients searching for central toxicity of cisplatin in the auditory pathways. 


\section{REFERENCES}

1. Berg AL, Spitzer JB, Garvin JH Jr. Ototoxic impact of cisplatin in pediatric oncology patients. Laryngoscope. 1999;109(11):180614. PMID: 10569412 DOI: http://dx.doi.org/10.1097/00005537199911000-00016

2. Hamers FP, Wijbenga J, Wolters FL, Klis SF, Sluyter S, Smoorenburg GF. Cisplatin ototoxicity involves organ of Corti, stria vascularis and spiral ganglion: modulation by alphaMSH and ORG 2766. Audiol Neurootol. 2003;8(6):305-15. DOI: http://dx.doi. org/10.1159/000073515

3. Steeghs N, de Jongh FE, Sillevis Smitt PA, van den Bent MJ. Cisplatin-induced encephalopathy and seizures. Anticancer Drugs. 2003;14(6):443-6. DOI: http://dx.doi.org/10.1097/00001813200307000-00009

4. Kusunoki J, Saito T. Neuropathy induced by antineoplastic drugs. Brain Nerve. 2008;60(2):131-6. PMID: 18306660

5. Penido NO, Mota PHM, Mascari DSA, Fukuda Y. Ototoxicidade induzida por cis-diamminedichloroplatinum (NSC - 119875). Acta Awho. 1989; (8):80-3.

6. De Lauretis A, De Capua B, Barbieri MT, Bellussi L, Passàli D. ABR evaluation of ototoxicity in cancer patients receiving cisplatin or carboplatin. Scand Audiol. 1999;28(3):139-43. PMID: 10489862 DOI: http://dx.doi.org/10.1080/010503999424707

7. Truong MT, Winzelberg J, Chang KW. Recovery from cisplatin-induced ototoxicity: a case report and review. Int J Pediatr Otorhinolaryngol. 2007;71(10):1631-8. PMID: 17706797 DOI: http://dx.doi. org/10.1016/j.jporl.2007.06.021

8. de Jongh FE, van Veen RN, Veltman SJ, de Wit R, van der Burg $\mathrm{ME}$, van den Bent MJ, et al. Weekly high-dose cisplatin is a feasible treatment option: analysis on prognostic factors for toxicity in 400 patients. Br J Cancer. 2003;88(8):1199-206. PMID: 12698184 DOI: http://dx.doi.org/10.1038/sj.bjc.6600884

9. Bokemeyer C, Berger CC, Hartmann JT, Kollmannsberger C, Schmoll HJ, Kuczyk MA, et al. Analysis of risk factors for cisplatin-induced ototoxicity in patients with testicular cancer. $\mathrm{Br} \mathrm{J}$ Cancer. 1998;77(8):1355-62. DOI: http://dx.doi.org/10.1038/bjc.1998.226

10. Coupland SG, Ponton CW, Eggermont JJ, Bowen TJ, Grant RM. Assessment of cisplatin-induced ototoxicity using derived-band ABRs. Int J Pediatr Otorhinolaryngol. 1991;22(3):237-48. PMID: 1752735 DOI: http://dx.doi.org/10.1016/0165-5876(91)90078-P

11. Stavroulaki P, Apostolopoulos N, Segas J, Tsakanikos M, Adamopoulos G. Evoked otoacoustic emissions--an approach for monitoring cisplatin induced ototoxicity in children. Int $\mathrm{J}$ Pediatr Otorhinolaryngol. 2001;59(1):47-57. PMID: 11376818 DOI: http:// dx.doi.org/10.1016/S0165-5876(01)00455-4

12. Lary S, Briassoulis G, de Vries L, Dubowitz LM, Dubowitz V. Hearing threshold in preterm and term infants by auditory brainstem response. J Pediatr. 1985;107(4):593-9. PMID: 4045608 DOI: http:// dx.doi.org/10.1016/S0022-3476(85)80030-5

13. Hall JW. Neurodiagnosis: central nervous system. In: Hall J W. Handbook of auditory evoked responses. Massachusetts: Allyn and Bacon; 1992. p.419-72.

14. Stelmachowicz PG, Pittman AL, Hoover BM, Lewis DE, Moeller MP. The importance of high-frequency audibility in the speech and language development of children with hearing loss. Arch Otolaryngol Head Neck Surg. 2004;130(5):556-62. DOI: http://dx.doi. org/10.1001/archotol.130.5.556
15. Yoshinaga-Itano C, Sedey AL, Coulter DK, Mehl AL. Language of early- and later-identified children with hearing loss. Pediatrics. 1998;102(5):1161-71. PMID: 9794949

16. Hansen SW, Helweg-Larsen S, Trojaborg W. Long-term neurotoxicity in patients treated with cisplatin, vinblastine, and bleomycin for metastatic germ cell cancer. J Clin Oncol. 1989;7(10):1457-61.

17. Rybak LP, Whitworth CA, Mukherjea D, Ramkumar V. Mechanisms of cisplatin-induced ototoxicity and prevention. Hear Res. 2007;226(12):157-67. PMID: 17113254

18. van Ruijven MW, de Groot JC, Hendriksen F, Smoorenburg GF. Immunohistochemical detection of platinated DNA in the cochlea of cisplatin-treated guinea pigs. Hear Res. 2005;203(1-2):112-21.

19. Meech RP, Campbell KC, Hughes LP, Rybak LP. A semiquantitative analysis of the effects of cisplatin on the rat stria vascularis. Hear Res. 1998;124(1-2):44-59.

20. Alam SA, Ikeda K, Oshima T, Suzuki M, Kawase T, Kikuchi T, et al. Cisplatin-induced apoptotic cell death in Mongolian gerbil cochlea. Hear Res. 2000;141(1-2):28-38. PMID: 10713493

21. Liang F, Schulte BA, Qu C, Hu W, Shen Z. Inhibition of the calciumand voltage-dependent big conductance potassium channel ameliorates cisplatin-induced apoptosis in spiral ligament fibrocytes of the cochlea. Neuroscience. 2005;135(1):263-71. PMID: 16109459 DOI: http://dx.doi.org/10.1016/j.neuroscience.2005.05.055

22. Husain K, Scott RB, Whitworth C, Somani SM, Rybak LP. Dose response of carboplatin-induced hearing loss in rats: antioxidant defense system. Hear Res. 2001;151(1-2):71-8.

23. García-Ruiz C, Colell A, Marí M, Morales A, Fernández-Checa JC. Direct effect of ceramide on the mitochondrial electron transport chain leads to generation of reactive oxygen species. Role of mitochondrial glutathione. J Biol Chem. 1997;272(17):11369-77.

24. Lewis MJ, DuBois SG, Fligor B, Li X, Goorin A, Grier HE. Ototoxicity in children treated for osteosarcoma. Pediatr Blood Cancer. 2009;52(3):387-91. DOI: http://dx.doi.org/10.1002/pbc.21875

25. Knight KR, Kraemer DF, Neuwelt EA. Ototoxicity in children receiving platinum chemotherapy: underestimating a commonly occurring toxicity that may influence academic and social development. J Clin Oncol. 2005;23(34):8588-96. DOI: http://dx.doi.org/10.1200/ JCO.2004.00.5355

26. Bertolini P, Lassalle M, Mercier G, Raquin MA, Izzi G, Corradini $\mathrm{N}$, et al. Platinum compound-related ototoxicity in children: long-term follow-up reveals continuous worsening of hearing loss. J Pediatr Hematol Oncol. 2004;26(10):649-55. DOI: http://dx.doi. org/10.1097/01.mph.0000141348.62532.73

27. Li Y, Womer RB, Silber JH. Predicting cisplatin ototoxicity in children: the influence of age and the cumulative dose. Eur $J$ Cancer. 2004;40(16):2445-51. PMID: 15519518 DOI: http://dx.doi. org/10.1016/j.ejca.2003.08.009

28. Kingston JE, Abramovich S, Billings RJ, Malpas JS, Fuller AP. Assessment of the effect of chemotherapy and radiotherapy on the auditory function of children with cancer. Clin Otolaryngol Allied Sci. 1986;11(6):403-9

29. Maiese K, Walker RW, Gargan R, Victor JD. Intra-arterial cisplatin--associated optic and otic toxicity. Arch Neurol. 1992;49(1):83-6. PMID: 1728268 DOI: http://dx.doi.org/10.1001/ archneur.1992.00530250087021 